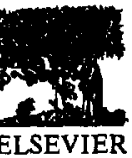

\title{
ANIMAL GENETIC RESOURCES IN BRAZIL: RESULT OF FIVE CENTURIES OF NATURAL SELECTION
}

\author{
A. da S. Mariante and A. A. Egito \\ Embrapa Genetic Resources and Biotechnology, Brasilia, Brazil
}

\begin{abstract}
Brazil has various species of domestic animals, which developed from breeds brought by the Portuguese settlers soon after their discovery. For five centuries, these breeds have been subjected to natural selection in specific environments. Today, they present characteristics adapted to the specific Brazilian environmental conditions. These breeds developed in Brazil are known as "Crioulo," "local," or naturalized. From the beginning of the 20th century, some exotic breeds, selected in temperate regions, have begun to be imported. Although more productive, these breeds do not have adaptive traits, such as resistance to disease and parasites found in breeds considered to be "native." Even so, little by little, they replaced the native breeds, to such an extent that the latter are in danger of extinction. In 1983, to avoid the loss of this important genetic material, the National Research Center for Genetic Resources and Biotechnology (Cenargen) of the Brazilian Agricultural Research Corporation (Embrapa) decided to include conservation of animal genetic resources in its research program Conservation and Utilization of Genetic Resources. Until this time, they were only concerned with conservation of native plants. Conservation has been carried out by various research centers of Embrapa, universities, state research corporations, and private farmers, with a single coordinator at the national level, Cenargen. Specifically, conservation is being carried out by conservation nuclei, which are specific herds in which the animals are being conserved, situated in the habitats where the animals have been subjected to natural selection. This involves storage of semen and embryos from cattle, horses, buffaloes, donkeys, goats, sheep, and pigs. The Brazilian Animal Germplasm Bank is kept at Cenargen, which is responsible for the storage of semen and embryos of various breeds of domestic animals threatened with extinction, where almost 45,000 doses of semen and more than 200 embryos exist presently. An important challenge for this program is to make the different segments of society realize the importance of the conservation of animal genetic resources.

Q 2001 by Elsevier Science inc.
\end{abstract}

Key words: conservation, "local breeds," "semen cryopreservation"

\section{INTRODUCTION}

Unlike cultivated plants, most domesticated livestock species were introduced to Brazil by successive waves of early exploration and colonization. Few domesticated animals existed in precolonial times, although indigenous peoples did domesticate a number of species. This lack of domestic animal diversity in the country, prior to European settlement, was indicated in a letter sent to the King of Portugal by Pero Vaz de Caminha, the official scribe of the first expedition to Brazil in the year 1500 . He described this new land by saying: 
"The people of this place do not plough, nor raise animals, nor are there oxen, nor cows, nor goats, nor sheep, nor hens, nor any other animal species which would normally share man's life. These people do not eat, if not for this yam, of which there are lots, and these seeds and fruits, that the land and the trees throw from themselves. And with this, they walk so strong and so vigorous that we are not as such, with all the wheat and vegetables that we eat."(1)

Presently, Brazil has various species of domestic animals, which developed from breeds brought by the Portuguese settlers soon after discovery. During almost five centuries, these breeds have been naturally selected in distinct environments, in such a way that, today, they present characteristics adapted to the specific environmental conditions. These breeds developed in Brazil are known as "Criollo," "local," or naturalized.

From the beginning of the 20th century, some exotic breeds, selected in temperate regions, were imported. Although more productive, these breeds did not have adaptive traits, such as resistance to disease and parasites found in breeds considered to be "native." Even so, little by little, they substituted the native breeds, to such an extent that the latter are, today, in danger of extinction. To avoid the loss of this important genetic material, in 1983 the National Research Center for Genetic Resources and Biotechnology (Cenargen) of the Brazilian Agricultural Research Corporation (Embrapa) decided to include conservation of animal genetic resources in its research program Conservation and Utilization of Genetic Resources, which, until then, had contemplated only plants.

Since then, conservation has been carried out by various research centers of Embrapa, universities, state research corporations, and private farmers, with a single coordinator at the national level, Cenargen. This program includes the following stages: a) identification of populations in an advanced stage of genetic dilution, b) phenotypic and genetic characterization of germplasm, and c) evaluation of productive potential. Conservation is being carried out by conservation nuclei situated in the habitats where the animals have been subjected to natural selection (in situ) and by the storage of semen and embryos (ex situ). An important challenge for this program is to make the different segments of society realize the importance of the conservation of animal genetic resources.

\section{CONSERVATION OBJECTIVES}

The main objectives of the conservation of animal genetic resources being carried out include the following: a) to identify and characterize phenotypically conservation nuclei, establishing "origin" centers, genetic diversity, and variability for the groups of animals in danger of extinction; b) to monitor existing animal conservation nuclei; c) to start new conservation nuclei of breeds that are identified as being in danger of extinction; d) to conserve ex situ genetic material by cryopreservation of semen and embryos; e) to genetically characterize the breeds involved in the program; and $f$ ) to increase the awareness of the diverse segments of society about the importance of the conservation of animal genetic resources. 


\section{BRAZILIAN ANIMAL GENETIC RESOURCES}

"Local" Breeds

With its continental dimensions, Brazil has a huge variety of ecosystems where the different species of domestic animals brought by the first settlers began to establish themselves. Through centuries of natural selection, these animals attained special adaptation features specific to the ecological niche where they developed. Little by little, these animals dispersed over the whole Brazilian territory and adapted to the very diverse environmental conditions with special characteristics such as in the Pampas of Rio Grande do Sul (huge flat fields, on the border with Uruguay and Argentina), the southern Brazilian Plateau, the Cerrado (Central Brazil savanna), the Amazon, the Mato Grosso Pantanal (a naturally flooded area on the border with Bolivia), the Northeastern Agreste (semi-arid region), and the Lavrado (Northern Brazil savanna, on the border with Venezuela).

Because of the increasing demand for food of animal origin, farmers from various developing countries decided to establish programs, which, inevitably, led to the dilution of the "local" germplasm by the use of intensive crossbreeding with animals of exotic breeds. Many of these programs failed, as the animals introduced had lower productive indices than the "local" breeds. This meant that a considerable number of farmers, in establishing their production systems, started to give a deserved importance to the "local" breeds because of their adaptation to the environment, usually hostile, of the tropical region.

\section{Zebu Breeds}

At the end of the 19th century, the introduction of animals, which up to then had been considered extremely exotic-the zebu, began. Today, these breeds are responsible for nearly the total meat production in the country, as purebred or crossbred animals. This encompasses the region from the latitude of São Paulo State and spreading to northern Brazil. The zebu started to be introduced into Brazil at the end of the 19th century. These animals, which originated in India, were crossed in the beginning with the local breeds. Little by little, the local breeds were absorbed. As a result, Brazil has today the largest zebu population in the world. Presently, in their country of origin, where they are considered sacred, they are raised freely and protected by the community until they die a natural death. Before the first importation of zebu cattle to the Southeastern region of Brazil, the southern temperate climate region had already imported British cattle breeds, which were highly productive. The latter did not have the same adaptation problems as animals in the tropical regions of the country. As in central Brazil, the British breeds introduced in the south of the country were used in crossbreeding schemes that absorbed the local breeds, leading again to a drastic reduction in the effective population size of the local breeds.

The expansion of the zebu breeds in Brazil is an undisputed reality. Today, about $80 \%$ of the Brazilian cattle population is made up of zebu cattle or their crosses with Criollo and European cattle. Although, until now, the conservation program has only been involved with the native breeds, as they are threatened with extinction, there is already a demand from the zebu breeders that these breeds also be included. This is due to the, almost total, domination of the Nellore 
breed in Central Brazil. Of the six principal zebu breeds that exist in Brazil, approximately $85 \%$ of the total number of animals registered is Nellore.

Another aspect is that the use of new technologies and more efficient methods in genetic improvement, has led to profound changes in the procedures used by the breeders in the selection and reproductive management of their herds. Since 1984, when the first Bull Summary was published (6), the breeders began to have more precise information about the genetic merit of each individual selected. This, together with techniques that allowed the increase in reproductive capacity of the genotypes of interest (artificial insemination, embryo transfer, and in vitro fertilization), has made the decision-making process more objective, especially when you refer to the choice of animals for reproduction and mating schemes.

From the beginning of the publication of the bull summaries, a large number of breeders placed greater emphasis on the productive traits (taken from the classification table of the summary), rather than qualitative traits, such as breed characteristics and type. Bulls, which may have been ignored by breeders because of one or more phenotypic traits, produced offspring with exceptional weight gains. This substantiated the fact that transmitted production traits were more important at slaughter. These bulls then became highly sought after by the artificial insemination centers. This situation resulted in the use of a small number of bulls, especially those classified as elite, which, certainty led to the reduction in genetic variability. Ironically, this bull classification is partially responsible for the reduction in genetic variation (4). These preoccupations on the part of the breeders led to the demand for the creation of a germplasm bank where semen of zebu breeds would be stored.

\section{FORMATION OF CONSERVATION NUCLEI}

The conservation nuclei, organized in the form of individual research projects, are located all over the country. The research projects, usually based in research centers near the habitats, attempted to rescue the small effective populations of the breeds in danger of extinction. The interaction of Cenargen with these conservation nuclei (germplasm banks) is made by contacts between the Product Germplasm Curator (based in Cenargen) and the curators of the germplasm banks (normally the research project leaders). In the present curatorship system, there are 22 Product Germplasm Curators at Cenargen. Among them, 2 are curators for farm animals: 1 for large species (cattle, buffaloes, horses, and asses) and 1 for small species (sheep, goats, and pigs).

The Product Germplasm Curators at Cenargen are charged with advising the technical head in relation to germplasm considered relevant to national agriculture and animal production. They work at national and international levels. Specifically, they work with the enrichment of knowledge and conservation of product germplasm. Among other functions, the Product Germplasm Curator has to promote, begin, and follow activities related to conservation, multiplication, and/or regeneration of germplasm of products under his responsibility. The curators of the germplasm banks have the responsibility to maintain the conservation nuclei as well as to multiply, regenerate, and distribute the germplasm. The breeds included in the Brazilian Conservation Program are shown in Table 1. 
Table 1. Species and breeds included in research projects in the Brazilian Program of Animal Genetic Resources Conservation - 2001.

\begin{tabular}{lll}
\hline \multirow{2}{*}{ Species } & Breed & Region of the country \\
& & \\
\hline Cattle & Mocho Nacional & Southeast \\
& Pantaneiro & Central-West (Pantanal) \\
& Curraleiro or Pé-duro & Northeast \\
& Criollo Lageano & South \\
\hline Buffaloes & Baio & North \\
& Carabao & North \\
\hline Donkeys & Jumento Nordestino (North-eastern donkey) & Northeast \\
& Jumento Brasileiro (Brazilian donkey) & Southeast \\
\hline Horses & Pantaneiro & Central-West (Pantanal) \\
& Lavradeiro & North \\
& Marajoara & North \\
\hline Buffaloes & Baio & North \\
& Carabao & North \\
\hline Goats & Canindé & Northeast \\
& Gurguéia & Northeast \\
& Moxotó & Northeast \\
& Marota & Northeast \\
& Repartida & Northeast \\
\hline Sheep & Criollo Lanado & Northeast \\
\hline Diverse species & Animal Gene Bank (AGB) & Central-West \\
\hline
\end{tabular}

New populations of endangered native breeds are constantly being identified to maintain these breeds. Some are very similar to breeds officially included in the in situ conservation program, and others have totally distinct characters. In general, these populations, which have been found in the last few years, are small populations. The strategy has been to include them initially in the cryopreservation program. This assures the storage of genetic material in the Animal Gene Bank (AGB) in Cenargen. At the same time, their blood is collected for use in genetic characterization.

The results of genetic characterization could reduce existing doubts about genotypic expression. As an example, we can cite the case of the Criollo Lageano, Franqueiro, and Junqueira cattle. All have huge horns, and some breeders insist that they are the same breed, but others treat them as separate breeds. With genetic characterization, strategies could be developed to define their genetics.

\section{GENETIC CHARACTERIZATION}

Animal domestication began 12,000 years ago, and, since then, a large group of subpopulations developed. This was a function of the adaptation to different environmental 
conditions with the migration of man. The existing variance between these subpopulations, called breeds, and the variance within each of them, represents genetic diversity within domestic breeds.

The primary unit of an animal genetic resource is the breed, lineage, or geographically defined population. Each breed is the product of evolution and adaptation. Different selection pressures are imposed by the climate, endemic parasites, disease, and nutrition as well as selection criteria imposed by man. The formation of a breed is probably associated with some loss of genetic diversity in the initial stages, as well as the concentration and eventual fixation of some specific characteristics.

In the last 10 to $15 \mathrm{yrs}$, it has been noted that the use and preservation of animal genetic resources are inseparable. There has been an increase in the awareness of the importance of domestic breeds for world biodiversity. This is important, as genes and gene combinations may be useful for agriculture in the future. The progress and future development of animal production for humans are dependent on the genetic variability between and within breeds. The form and frequency of allelic forms is the basis of genotypic variation (2). Thus, the loss of a unique breed compromises access to its genes and unique genetic combinations (7). To this end, the present day vision is for the maintenance of maximum diversity in the genetic pool of each breed. This protects against genetic loss for the development of sustainable production systems. Because it is impossible to predict with objectivity which traits may be necessary in the future $(1,3,7)$, as many as possible should be conserved.

The characteristics that the naturalized breeds developed because of the natural selection that they maintained permitted their survival in certain tropical regions. In this way, the detailed study of naturalized breeds using genetic characterization of their populations may help in the rational development of future animal breeding programs, as well as the preservation and conservation of this important germplasm. The gains in economic efficiency, which may result from the use of this genetic material, will hopefully be greater than the costs of conservation of these breeds/populations.

For a long time the characterization of different breeds of domestic animals in Brazil was based, almost exclusively, on phenotypic data (morphology and production). This is sometimes insufficient to distinguish between pure breeds and is heavily influenced by environmental factors. With reference to genetic characterization, the few papers that have been published on Brazilian native breeds include only cytogenetic studies, blood groups, and protein polymorphisms.

Taking into consideration the lack of genetic characterization of naturalized breeds, Cenargen established the Animal Genetics Laboratory in 1998. Studies involving DNA polymorphisms are planned, and the mission of the laboratory is to genetically characterize and evaluate species and/or breeds that are in danger of extinction as well as commercial breeds with the intent to maintain, conserve, and make available the genetic diversity of the former.

It is known that although some naturalized breeds have different names and inhabit different regions, they have similar phenotypes. This raises doubts about their identity as a distinctive 
breed group or native type. These populations may or may not be genetically similar. Even if they belong to the same breed, because of geographical isolation or their adaptation to different ecological niches, they may have accumulated different alleles because of genetic drift. Therefore, genetic characterization would permit the identification of these unique genetic groups, which for a long time were isolated in their environments.

Because a complete description of the differences between two breeds/populations is not viable, the first step for the genetic characterization of naturalized breeds is to estimate the genetic uniqueness of these populations. The genetic difference between the populations is one of the criteria that may be used, as this is considered an objective and viable descriptor of the differentiation of the populations. The determination of the degree of genetic similarity or dissimilarity between the populations may help in deciding which populations should be conserved. This is especially important when resources are scarce, thereby avoiding the duplication of efforts in maintenance of samples of breeds. On the other hand, it assures the maintenance of genetic variability, avoiding the culling of populations of the same breed during the conservation process, which have particular characteristics. The final choice of breeds and individuals to be conserved should take into consideration all information on a) traits of economic interest, b) adaptation characteristics, c) presence of unique genes, and d) the importance of the breed in local or regional production systems.

Taking into consideration that the origin of the naturalized cattle breeds found in Brazil is the Iberian Peninsula, a scientific cooperation project is being implanted between Portugal and Brazil. This will help in the determination of which autochtone (native) Portuguese breed participated in the formation of the naturalized Brazilian breeds. The results achieved will permit the possibility of future exchanges of germplasm, which may be fundamental for the preservation of some of these Brazilian breeds, which at the present time have their effective population size severely reduced. Contacts are also being made with Spain for the same purpose.

\section{CRYOPRESERVATION}

As stated previously, in 1983 Cenargen decided to include conservation of animal genetic resources in its research program Conservation and Utilization of Genetic Resources, which, until then, contemplated only plants. One of the reasons to include animals in its conservation program was due to the fact that the Mocho Nacional cattle breed's entire surviving population consisted of three bulls and eight cows found in the states of São Paulo and Minas Gerais. Immediately, some veterinarians were hired and began to collect semen and embryos. It was perhaps fortunate that this breed had a small number of individuals for successful multiplication (10). In addition, it possessed a genetic trait that is dominant and useful, the polled gene.

The reproduction team working on conservation of animal genetic resources increased and started to develop new techniques. Two laboratories were then established: one for the development of these new techniques, utilizing the mouse as a biological model, and another to apply the developed techniques on large animals at Cenargen's experimental farm. Techniques on collection and freezing semen on farm, collection of embryos (surgically at the beginning), freezing/thawing and transferring embryos to recipient cows, micromanipulation of embryos, and 
permitting the production of identical twins from a single embryo were successfully developed. More recently, IVF and cloning were also developed in these labs, which show the stage of maturity of this research team.

To avoid the disappearance of local breeds around the world, FAO (Food and Agriculture Organization of the United Nations) began contacts in 1987 to install regional animal gene banks (RAGBs) for developing countries. At that time, Cenargen had been chosen to host the bank that would be responsible for the storage of semen and embryos of the breeds of domestic animals in danger of extinction in South America. A copy of the material would be stored in INTA (National Institute of Technology in Agriculture of Argentina) for security reasons. Because of health legislative differences, which regulate the entry and exit of genetic material between countries, none of these RAGBs were founded. There is a need to arrive at a common denominator, so that the future exchange of germplasm is facilitated, as the RAGBs have no commercial end, just storage for future use. The RAGBs were also proposed for Asia and Africa. The FAO found the same difficulty in those continents, which meant that the creation of the RAGBs had to be delayed.

In Brazil, the conservation of animal genetic resources was not prejudiced because when FAO proposed the creation of the RAGBs, Brazil had already created its own animal germplasm bank (AGB). The Brazilian AGB is kept at Cenargen, which is responsible for the storage of semen and embryos of various breeds of domestic animals threatened with extinction in Brazil.

Conservation nuclei must exist for semen, embryos, and oocytes of the species/breeds in danger of extinction to be collected. For this reason, both in situ and ex situ conservation (cryopreservation) are extremely important and complementary. Therefore, efforts generally are to do this locally; however, when this is not possible, some animals are temporarily transferred to Cenargen's experimental farm for the collection of semen embryos and oocytes. Table 2 shows the present state of the Brazilian AGB. 
Table 2. Number of semen doses and embryos stored in the animal germplasm bank of Cenargen in 2001 .

\begin{tabular}{llc}
\hline & & \\
Species/Breed & No. of semen doses & No. of embryos \\
Cattle & & \\
Criollo Lageano & 11,456 & 9 \\
Mocho Nacional & 7,382 & 54 \\
Caracu & 7,486 & 47 \\
Curraleiro & 8,359 & 17 \\
Criollo Argentino & 560 & - \\
Pantaneiro & 6,076 & 20 \\
Junqueira & 1,972 & 4 \\
Patuá & 245 & - \\
Goats & & \\
Moxotó & 546 & - \\
Canindé & 109 & - \\
Sheep & & \\
$\quad$ Criollo Lanado & 500 & 56 \\
Horses & & 1 \\
$\quad$ Pantaneiro & - & - \\
Donkeys & & \\
J. Nordestino & 150 & 208 \\
\hline Total & 44,841 & \\
\hline
\end{tabular}

For some breeds included in the Brazilian program, there are fewer donor bulls than the 25 donors per breed, with 100 doses/bull recommended (9). Unfortunately, when the ex situ conservation program began, some of the breeds did not have this number of males. Therefore, more than the recommended 100 doses/bull has been collected when the number of bulls was reduced. In other cases, such as the Argentine Criollo, this was not a Brazilian breed. Its use in Brazil is not common (although some bulls were used on the Criollo Lageano of the Fazenda Canoas, Santa Catarina State), it was decided to stop the collection, and the semen already collected was kept by the AGB. As the conservation nuclei are increased in size and number or new herds are identified, the intention is to collect genetic material from the greatest possible number of animals, thercby increasing the genetic variability in the AGB.

\section{PUBLIC AWARENESS}

Another objective of the program is to make the various sectors of society aware of the importance of conservation of animal genetic resources. Presenting the program on various opportunities has done this. In this way, the Brazilian program has been presented in different events in Brazil and abroad. In Brazil, the intention is to bring the philosophy of the work with animal conservation to society, as well as the actual state of development of the program (often 
stimulating the creation of new conservation nuclei); abroad, the intention is a) to show the state of animal genetic resources conservation in Brazil, stimulating the creation of new national gene banks and b) to present the actual conservation situation on the continent as a whole. It is hoped that the awareness level of society on the importance of conservation of animal genetic resources is being raised at both the national and international level.

Because the conservation of animal genetic resources is a relatively new topic, it has only recently been included in the programs of congresses and symposia. Until recently, the researchers who dared to breach this topic were labeled as philosophers. It was said that the socalled "native" breeds should be conserved in zoological gardens. Fortunately, this point of view is changing rapidly, and the most important congresses in the animal area are including sessions or symposia on this topic. At last, traits such as adaptation, rusticity, disease, and parasite resistance, which many of these breeds have, are being recognized and valued.

The creation of a farm park, as has occurred in several European countries, will be another strategy to bring this theme to the public attention. In 1993, the AGB was recognized by the Brazilian Ministry of Agriculture, who donated an area of 900 ha for the installation of a farm park, which will be called "Farm Park for the Animal Diversity in Brazil." The main objective of this park will be to unite, in Brasilia, live examples of domestic animal breeds of different species (cattle, buffaloes, horses, asses, sheep, goats, pigs, and poultry), which are in danger of extinction. This farm park will be open to the public and is already being built on Cenargen's experimental farm. At present, a large number of the animals that will be shown at the farm park have alrcady bcen brought to Brasilia and are being used for semen and embryo collection, which are been stored in the AGB. Table 3 shows the number of animals of the various species/breeds that can be found in Brasilia and that will be part of the farm park. 
Table 3. Number of animals of the various breeds maintained on Cenargen's experimental farm in 2001.

\begin{tabular}{|c|c|c|}
\hline Species/Breed & Number of Males & Number of Females \\
\hline \multicolumn{3}{|l|}{ Cattle } \\
\hline Caracu & 1 & 1 \\
\hline Criollo Lageano & 1 & 5 \\
\hline Curraleiro & 7 & 10 \\
\hline Junqueira & 2 & 3 \\
\hline Mocho Nacional & 1 & 1 \\
\hline Pantaneiro & 6 & 18 \\
\hline Patuá & 1 & 2 \\
\hline Puganu & 1 & 1 \\
\hline \multicolumn{3}{|l|}{ Goats } \\
\hline Azul & 1 & 4 \\
\hline Canindé & 2 & 3 \\
\hline Marota & 3 & 6 \\
\hline Moxotó & 3 & 8 \\
\hline Nambi & 2 & 2 \\
\hline Repartida & 1 & 4 \\
\hline \multicolumn{3}{|l|}{ Sheep } \\
\hline Criollo Lanado & 2 & 4 \\
\hline Marota & 2 & 2 \\
\hline \multicolumn{3}{|l|}{ Horses } \\
\hline Campeiro & 2 & 6 \\
\hline Pantaneiro & 4 & 5 \\
\hline \multicolumn{3}{|l|}{ Donkeys } \\
\hline Jumento Nordestino & 2 & 5 \\
\hline \multicolumn{3}{|l|}{ Pigs } \\
\hline Casco de Mula & 1 & 1 \\
\hline Inhata & $i$ & 2 \\
\hline Monteiro & 1 & 2 \\
\hline Moura & 1 & 1 \\
\hline Nilo & 1 & 2 \\
\hline Piau & 1 & 1 \\
\hline Rabo de Peixe & 1 & 2 \\
\hline Total & 51 & 104 \\
\hline
\end{tabular}




\section{CONCLUSIONS}

Normally, researchers or lecturers in animal breeding cannot visualize the importance of conservation of animal genetic resources. Nevertheless, Professor Jonas Pereira of the Federal University of Minas Gerais concluded a chapter of his book on animal breeding (8), which translates perfectly the feelings of the conservationists.

"In a highly competitive economy, which demands high efficiency for each activity, it is difficult to believe that private companies can be convinced of the need to preserve native breeds which are in danger of extinction. The association of the use of native breeds with the poverty of the producers and genetic lag of the exploration is common. In truth, from the strictly economic point of view, it is unsustainable to defend the rearing of native animals in view of the limited genetic potential of their germplasm, especially when compared with those improved and more profitable breeds. Nonetheless, the preservation of these genetic groupings has its historical side, which is the "genetic memory" of animals that helped to colonize the country. In a more or less intensive form, there are still remains of all of these breeds, through their crossbreds. It must be said that if these breeds were able to overcome, after dozens of generations of natural selection, the environmental adversaries to whom they were subjected, it is because they unite genotypes, which are compatible with the most diverse conditions. Also, man's intervention in their reproductive and selection processes were, at most, modest and did not cause any appreciable modification in their potential, other than those received from nature. Another aspect, which deserves consideration, is in relation to the proper dynamics of natural selection, which turns these native germplasms into authentic genetic reserves, especially when selection provokes the exhaustion of additive genetic variation and there is no more response in the animal breeding programs. The tremendous development of molecular biology and its future possibilities with the insertion of genes of native breeds into the specialized ones, modifying them for better performance than exotic germplasms in more hostile environments, makes their conservation justified in itself".

It is important to emphasize that the Brazilian program for the conservation of animal genetic resources is meeting its objectives, conserving in situ and ex situ valuable genetic material that exists in the country, characterizing it genetically, and revealing its importance to the various segments of society. The researchers involved in animal conservation are fully aware that the stored material will be their legacy to future generations.

\section{REFERENCES}

1. Barker JSF. A global protocol for determining genetic distances among domestic livestock breeds. In: World Congr Genet Appl Livest Prod 1994;5:501-508.

2. Danell B. Methods of conservation of farm animals. In: Genetic Resources in Farm Animals and Plants. Report from Research Symposium 27-29 May, The Nordic Council of Ministers, 1994;102-111.

3. Hall SJG, Bradley DG. Conserving livestock breed biodiversity. Tree 10 1995;7:267-270. 
4. Mariante AS. O futuro de uma raça especializada de gado de corte: seleção versus variabilidade genética. In: Bovinocultura de Corte. Campinas, SP: SBZ, 1990;109-112.

5. Mariante AS, Cavalcante N. Animals of the Discovery: Domestic breeds in the History of Brazil. Mariante AdaS, Cavalcante, N. (eds). Embrapa, 2000.

6. Mariante AS, Nobre PRC, Silva LOC, Rosa AN, Figueiredo GR. Resultados do controle de desenvolvimento ponderal. I. Nelore. Campo Grande, Embrapa-CNPGC, Documentos, 18, 1984.

7. National Research Council. Managing Global Genetic Resources. Committee on Managing Global Genetic Resources: Agricultural Imperatives. Washington, DC: National Academic Press, 1993:276.

8. Pereira JCC. Melhoramento genético aplicado à produção animal. Belo Horizonte 1996.

9. Smith C. Genetic aspects of conservation in farm livestock. Livest Prod Sci 1984;11(1):2336.

10. Yamada Y, Kimura K. Survival probability in small populations. In: FAO Animal Production and Health Paper, 1984;44(1):105-110. 